Article

\title{
Phase Transformation-Induced Improvement in Hardness and High-Temperature Wear Resistance of Plasma-Sprayed and Remelted NiCrBSi/WC Coatings
}

\author{
Jin Sha ${ }^{1}$, Liang-Yu Chen ${ }^{1, *}$, , Yi-Tong Liu ${ }^{1}$, Zeng-Jian Yao ${ }^{2}$, Sheng Lu ${ }^{1, *}$, Ze-Xin Wang ${ }^{1}$, \\ Qian-Hao Zang ${ }^{1}$, Shu-Hua Mao ${ }^{1}$ and Lai-Chang Zhang ${ }^{3, *(D)}$ \\ 1 School of Materials Science and Engineering, Jiangsu University of Science and Technology, \\ Zhenjiang 212003, China; shajin202012@126.com (J.S.); 18252589582@163.com (Y.-T.L.); \\ xxkissbaby@126.com (Z.-X.W.); sdu_zangqianhao@126.com (Q.-H.Z.); zjw_mumu@126.com (S.-H.M.) \\ 2 National Dies and Molds Quality Supervision Test Center, No. 1288, Chengbei Zhong Road, \\ Kunshan 215300, China; zengjianyao@126.com \\ 3 School of Engineering, Edith Cowan University, 270 Joondalup Drive, Joondalup, Perth, WA 6027, Australia \\ * Correspondence: lychen@just.edu.cn (L.-Y.C.); lusheng_ktz@just.edu.cn (S.L.); 1.zhang@ecu.edu.au (L.-C.Z.)
}

Received: 8 November 2020; Accepted: 14 December 2020; Published: 17 December 2020

\begin{abstract}
The remelting method is introduced to improve the properties of the as-sprayed NiCrBSi coatings. In this work, tungsten carbide (WC) was selected as reinforcement and the as-sprayed and remelted $\mathrm{NiCrBSi} / \mathrm{WC}$ composite coatings were investigated by $\mathrm{X}$-ray diffraction, scanning electron microscopy, hardness test and tribology test. After spraying, WC particles are evenly distributed in the coating. The remelting process induced the decarburizing reaction of $\mathrm{WC}$, resulting in the formation of dispersed $\mathrm{W}_{2} \mathrm{C}$. The dispersed $\mathrm{W}_{2} \mathrm{C}$ particles play an important role in the dispersion strengthening. Meanwhile, the pores and lamellar structures are eliminated in the remelted NiCrBSi/WC composite coating. Due to these two advantages, the hardness and the high-temperature wear resistance of the remelted NiCrBSi/WC composite coating are significantly improved compared with those with an as-sprayed NiCrBSi coating; the as-sprayed NiCrBSi coating, as-sprayed NiCrBSi/WC composite coating and remelted NiCrBSi/WC composite coating have average hardness of 673.82 , $785.14,1061.23 \mathrm{HV}$, and their friction coefficients are $0.3418,0.3261,0.2431$, respectively. The wear volume of the remelted $\mathrm{NiCrBSi} / \mathrm{WC}$ composite coating is only one-third of that of the as-sprayed NiCrBSi coating.
\end{abstract}

Keywords: NiCrBSi; plasma spraying; remelting; hardness; wear

\section{Introduction}

Some moving parts in industrial machinery, such as aero engines, gas turbines, turbochargers and so on, are employed in a high-temperature environment. Such parts are always subjected to significantly severe high-temperature wear [1]. Therefore, it is necessary to improve their wear resistance in such environments. Generally, surface modification methods for improving wear resistance include thermal spraying [2-4], laser processing [5-8], friction stir processing [9,10], micro-arc oxidation [11], shot peening $[12,13]$ and so on. Among these methods, thermal spraying is an efficient technology to produce reliable coatings on the workpieces [14]. Plasma spraying is one of the thermal spraying technologies and prepares coatings to improve the wear resistance and hardness of metallic parts. Using plasma spraying technology to prepare composite coatings can further improve their hardness and wear resistance [15-19].

In order to meet the requirements of high wear resistance and hardness of the coating, nickel-based self-melting alloys are frequently used [20-22]. The NiCrBSi alloy (one of the nickel-based self-melting 
alloys) has special advantages at a high temperature, such as the ability to dissolve more elements, the formation of coherent and ordered strengthening phases and maintaining the stability of microstructure [23]. In this alloy, Si and B mainly play the roles in wetting and reducing the melting point of $\mathrm{NiCrBSi}, \mathrm{Cr}$ is used to improve the corrosion resistance and oxidation resistance of the alloy, and C, B as well as Fe play an important role in improving the hardness and wear resistance of the NiCrBSi alloy [24,25]. When the content of B is high enough, there are boride and carbide precipitates. Hence, the NiCrBSi alloy is further strengthened. However, the properties of NiCrBSi alloy cannot be endlessly enhanced by adjusting the contents of the elements. Therefore, for further improving the hardness and wear resistance of NiCrBSi coating, the addition of a ceramic particle is an effective method [26-28]. Tungsten carbide (WC) is the important reinforcement for the preparing high wear-resistant coatings by plasma spraying [29,30]. A certain amount of WC powder was added to the NiCrBSi powder by mechanical mixing to obtain the NiCrBSi/WC composite. The previous studies show that $\mathrm{NiCrBSi} / \mathrm{WC}$ composite coating has enhanced properties as compared to the $\mathrm{NiCrBSi}$ coating [30]. Therefore, considerable attention has been paid. Rachidi et al. [31] prepares NiCrBSi and $\mathrm{NiCrBSi}-\mathrm{WC}$ coatings by oxyacetylene flame spraying - their results show that the NiCrBSi coating with $60 \%$ WC has significantly high hardness $(1200 \mathrm{HV})$ which is almost twice that of the NiCrBSi coatings. Zhu et al. [32] studied the effect of different WC contents on the high-temperature wear behavior of $\mathrm{NiCrBSi} / \mathrm{WC}$ coatings. When the WC content is fewer than $20 \%$, the wear rate would decrease with increasing the WC content. In comparison, if the WC content is more than $20 \%$, the wear rate of the coating would increase significantly. Guo et al. [30] produced NiCrBSi coating and NiCrBSi/WC-Ni composite coating on stainless steel by laser cladding. The friction and wear behavior of the laser cladding coatings sliding against $\mathrm{Si}_{3} \mathrm{~N}_{4}$ ball at an elevated temperature of $500{ }^{\circ} \mathrm{C}$ was evaluated. They found that the microhardness and wear resistance of the laser-cladded coatings are excellent than those of stainless-steel substrate. In particular, laser-cladded NiCrBSi/WC-Ni composite coatings show better high temperature wear resistance than NiCrBSi coatings, which is due to the decomposition of WC grains. The WC grains would transform to the $\mathrm{W}_{2} \mathrm{C}$ grains at high temperature and the $\mathrm{W}_{2} \mathrm{C}$ grains have higher hardness than WC grains [33]. Therefore, the laser-cladded NiCrBSi/WC-Ni composite coating maintains the high wear resistance at a high temperature [30].

The above results raise a new question: can the properties of $\mathrm{NiCrBSi} / \mathrm{WC}$ composite coating be further improved? As is well known, due to the intrinsic characteristics of this technology, the plasma-sprayed coatings have a large number of flaws, such as pores and unmelted particles, which affects the hardness and wear resistance of the coatings [3,34-37]. Meanwhile, the amorphous phase is always found in NiCrBSi coatings, which results from the fast cooling of melted particle during deposition and decrease the volume fractions of hard phases, resulting in the reduction in the hardness and wear resistance $[4,38,39]$. As is known, the amorphous phase is metastable [40-42]. Crystallization of amorphous phase easily takes place in case of inputting external energy [43-46]. Hence, post-heat treatment and remelting were used to decrease the volume fraction of amorphous phase in the as-sprayed NiCrBSi coatings [4,47]. In comparison, remelting could eliminate the flaws in the as-sprayed NiCrBSi coatings but post-heat treatment has little effect on the flaws. Therefore, a variety of remelting methods are developed to remelt the as-sprayed NiCrBSi coatings, which may improve their properties. At present, common methods, such as laser, electron beam, tungsten pole argon arc, flame, induction and so on, have been used to remelt the as-sprayed NiCrBSi coatings [48-52]. Serres et al. [48] combined atmospheric plasma spraying and in-situ laser processes to modify the structural characteristics of thick NiCrBSi alloy coatings. The results showed that in-situ laser remelting induces the growth of a dendritic structure, which increases the adhesion of coatings on the substrate. A mechanical investigation demonstrated that the combination of plasma spray and in situ melting with a diode laser could result in the good mechanical properties of NiCrBSi alloy coating. Dong et al. [53] studied the rolling/sliding contact fatigue behavior of the coatings under different stresses. The results indicated that the induction remelting improves the microstructure and hardness of the NiCrBSi coating, and changes the coating/substrate interface bonding from mechanical bonding to metallurgical 
bonding. Chen et al. [47] remelted the plasma-sprayed NiCrBSi coatings by plasma arc, which is a convenient and low-cost method. This method significantly improves the hardness, wear resistance and bond strength of the NiCrBSi coating. Due to its reliability, repeatability and convenience, it is very promising for a wider range of industrial applications. Therefore, the properties of the as-sprayed $\mathrm{NiCrBSi} / \mathrm{WC}$ composite coating may be enhanced by this method. Unfortunately, there is still lack of investigation of the remelted $\mathrm{NiCrBSi} / \mathrm{WC}$ composite coating prepared by plasma arc.

Therefore, in this work, the as-sprayed NiCrBSi coating and NiCrBSi/WC composite coating were prepared by plasma spraying. Subsequently, the NiCrBSi/WC composite coating was remelted by a plasma arc using the same equipment. The microstructures of the coatings were investigated. Meanwhile, their hardness and high-temperature wear behavior were examined. Based on the results, the strengthening mechanism was discussed.

\section{Materials and Methods}

\subsection{Sample Preparation}

NiCrBSi alloy powder used in the work was purchased from the BGRIMM Advanced Materials Science and Technology Co., Ltd. in Beijing, China. NiCrBSi/WC composite coating was prepared by mixed nickel-coated tungsten carbide (WC-12Ni) and NiCrBSi powder with a mass fraction ratio of 35 and $65 \%$. WC-12Ni was purchased from the same company. The mixture was prepared by mechanical mixing using a planetary muller (QM-3SP2, Nanjing Chi Shun Technology Development Co.,Ltd. in Nanjing, China) with a rotation speed of $120 \mathrm{rpm}$ for $1 \mathrm{~h}$. Then, 2Cr13 martensitic stainless steel was used as substrate. The chemical compositions of powder and substrate are shown in Table 1.

Table 1. Compositions of NiCrBSi, Tungsten Carbide (WC)-12Ni Powder and 2Cr13 Stainless Steel (wt.\%).

\begin{tabular}{cccccccc}
\hline Component & Cr & B & Si & Fe & C & W & Ni \\
\hline NiCrBSi & 16.2 & 3.0 & 4.5 & 5.3 & 0 & - & Bal. \\
WC-12Ni & - & - & - & - & 5.4 & 82.6 & 12.0 \\
2Cr13 stainless steel & 13.0 & - & 0.8 & Bal. & - & - & 0.6 \\
\hline
\end{tabular}

Due to the significant influence of the roughness of substrates on the adhesion between coatings and substrates, the substrates were sandblasted with alumina after polishing to a mirror surface [4]. During the spraying and remelting process, an SG-100 plasma-spraying torch (Praxair, Inc., Danbury, CT, USA) was employed. Argon was used as a carrier gas to transport the powder from the powder feeder to the plasma torch to prevent the powder from being oxidized. Using the spraying parameters listed in Table 2, the as-sprayed NiCrBSi and NiCrBSi/WC coatings were prepared. The remelting process began at the end of spraying process. When the as-sprayed coating was prepared on a substrate, the powder feeder was turned off and the as-sprayed coating was remelted using plasma arc after moving the plasma gun to a distance of $40 \mathrm{~mm}$ to the coating. The whole remelting time was about $2.5 \mathrm{~min}$. After remelting, the remelted samples were cooled in air. The detailed remelting parameters are shown in Table 2. Herein, the as-sprayed NiCrBSi, NiCrBSi/WC composite, and the remelted $\mathrm{NiCrBSi} / \mathrm{WC}$ were named as SP-NiCrBSi, SP-NW35 and RE-NW35, respectively. 
Table 2. Plasma Spraying and Remelting Parameters.

\begin{tabular}{cccc}
\hline Parameters & SP-NiCrBSi & SP-NW35 & RE-NW35 (Remelting) \\
\hline Power $(\mathrm{kW})$ & 30 & 30 & 35 \\
Distance to the substrate $(\mathrm{mm})$ & 80 & 90 & 40 \\
Main gas Ar $(\mathrm{psi})$ & 80 & 90 & 80 \\
Secondary gas $\mathrm{dm}_{2}\left(\mathrm{dm}^{3} / \mathrm{s}\right)$ & 1 & 1 & 1 \\
Time $(\mathrm{min})$ & 1.5 & 2 & 2.5 \\
Spray step $(\mathrm{mm})$ & 3 & 3 & 3 \\
Powder feed rate $(\mathrm{g} / \mathrm{s})$ & 0.3 & 0.3 & - \\
Gun traverse rate $(\mathrm{mm} / \mathrm{s})$ & 100 & 100 & 10 \\
\hline
\end{tabular}

\subsection{Microstructural Characterizations}

The test pieces were ground with sandpaper from 400 to 2000 grits and polished with $1.5 \mu \mathrm{m}$ diamond paste to a mirror finish. The microstructures of the coatings were examined by scanning electron microscopy (SEM, JSM-6480, JEOL, Osaka, Japan) equipped with energy dispersive spectroscopy (EDS) detector. The porosities of coatings were defined by the software Image J2X using SEM images. The SEM images were binarized and the pores were represented by a single color. This method was in accordance with the ASTM Standard E2109-01 [54]. The phase constituents of the coatings prepared under different conditions was carried out using $\mathrm{X}$-ray diffraction diffractometer (XRD, XRD-6000, Shimadzu, Japan) with Cu target. The specific parameters are as follows: accelerating voltage is $40 \mathrm{kV}$, the scanning speed is $4 \% \mathrm{~min}$ and the scanning range is from 30 to $90^{\circ}$. The Jade 6.5 software (Materials Data, Inc., Santa Clara, CA, USA) was used to analyze the XRD data.

\subsection{Adhesion Strength, Microhardness and Tribology Test}

The coating adhesion strength was measured according to ASTM C633-79 standard [55]. The samples coated with the coating $(\Phi 25 \mathrm{~mm})$ was glued to a stainless steel with the same diameter coating using resin glue. At least three samples were tested. Surface hardness of the coatings was measured by an automatic hardness tester (KB30S, KB PRUEFTECHNIK GMDH, Assenheim German). The load for indentation was $100 \mathrm{gf}$ with the dwell time of $10 \mathrm{~s}$. Hardness was tested for each sample at least 10 times.

Tribology test was conducted on a friction and wear testing machine (UMT-2, Bruker, Germany) without lubrication. The contact form was point contact and movement form was circular motion. Sample was size $15 \mathrm{~mm} \times 1 \mathrm{~mm} \times 10 \mathrm{~mm}$ and all samples were polished before tribology test. $\mathrm{Si}_{3} \mathrm{~N}_{4}$ ceramic balls with a diameter of $9.38 \mathrm{~mm}$ were selected as the friction pair material. The specific test parameters were as follows: the load was $25 \mathrm{~N}$, the rotational speed was $500 \mathrm{r} / \mathrm{min}$, time was $30 \mathrm{~min}$, the radius was $4 \mathrm{~mm}$ and the temperature was set to $600^{\circ} \mathrm{C}$. The worn surfaces of different coatings as well as the debris were examined by SEM. The areas of the wear tracks were measured by confocal laser sweep microscope (OLS 4000, OLYMPUS, Tokyo, Japan). As a result, the wear volume can be obtained by the formula as follows:

$$
\mathrm{V}=\mathrm{S} \times \mathrm{L}
$$

where $\mathrm{V}$ is the wear volume, $\mathrm{S}$ is the wear mark cross section area and $\mathrm{L}$ is the total length of wear mark track.

\section{Results and Discussion}

\subsection{Microstructure Features}

Figure 1 shows the XRD patterns of the coatings. It can be seen that the SP-NiCrBSi coating is mainly composed of $\gamma-\mathrm{Ni}, \mathrm{Ni}_{3} \mathrm{~B}, \mathrm{CrB}, \mathrm{Cr}_{7} \mathrm{C}_{3}$ and $\mathrm{Cr}_{3} \mathrm{C}_{2}$. A broaden diffuse diffraction is found from 40 to $50^{\circ}$ in the XRD pattern of SP-NiCrBSi, indicating the presence of crystallite/amorphous 
phase $[42,56,57]$. The presence of crystallite/amorphous is the main factor causing the broadening of peak, due to their strong scattering effect to X-ray [58,59]. In our previous work, the broadening is demonstrated as the amorphous phase and $\gamma$-Ni crystallite in the as-sprayed NiCrBSi coating, which is a result of the fast cooling of in-flight particles during deposition [4]. The SP-NW35 coating mainly consists of $\gamma-\mathrm{Ni}, \mathrm{Ni}_{3} \mathrm{~B}, \mathrm{CrB}, \mathrm{Cr}_{7} \mathrm{C}_{3}, \mathrm{Cr}_{3} \mathrm{C}_{2}, \mathrm{WC}, \mathrm{WC}_{1-\mathrm{x}}$ and $\mathrm{W}_{2} \mathrm{C}$. During the spraying process, the solid WC particles are decarburized in plasma arc at a high temperature and hence some WC reinforcements would transform into $\mathrm{W}_{2} \mathrm{C}$ by the decarbonization of $2 \mathrm{WC} \rightarrow \mathrm{W}_{2} \mathrm{C}+\mathrm{C}$ [29]. Therefore, both WC and $\mathrm{W}_{2} \mathrm{C}$ peaks are observed in the XRD patterns of SP-NW35. However, $W_{1-x}$ peak is detected, illustrating the incomplete decarbonization of WC during spraying and deposition $[60,61]$. After remelting, the RE-NW35 coating mainly consists of $\gamma-\mathrm{Ni}, \mathrm{Ni}{ }_{3} \mathrm{~B}, \mathrm{CrB}, \mathrm{Cr}_{7} \mathrm{C}_{3}, \mathrm{Cr}_{3} \mathrm{C}_{2}, \mathrm{WC}, \mathrm{WC}_{1-\mathrm{x}}$ and $\mathrm{W}_{2} \mathrm{C}$. Compared with the XRD pattern of the SP-NW35 coating, the diffraction peaks of $\mathrm{W}_{2} \mathrm{C}$ become more intense in the RE-NW35 coating, indicating the further formation of $\mathrm{W}_{2} \mathrm{C}$ during remelting.

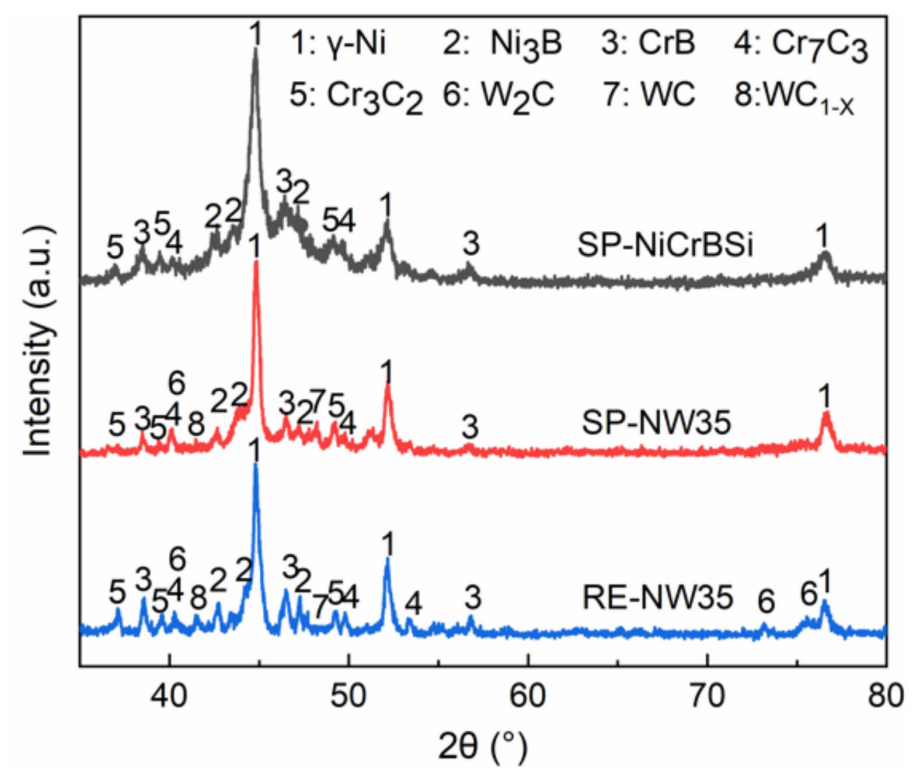

Figure 1. XRD patterns of the SP-NiCrBSi, SP-NW35 and RE-NW35 coatings. SP-NiCrBSi and SP-NW35 indicates the as-sprayed NiCrBSi and NiCrBSi/WC coatings; RE-NW35 means the remelted $\mathrm{NiCrBSi} / \mathrm{WC}$ coating.

Figure 2 shows the SEM images of cross-sectional morphologies of (Figure 2a,b) SP-NiCrBSi, (Figure 2c,d) SP-NW35 and (Figure 2e,f) RE-NW35. Figure 2a shows the typical microstructure of the as-sprayed NiCrBSi coating. The pores (as indicated by solid arrows) are randomly distributed in the SP-NiCrBSi coating and the porosity of SP-NiCrBSi is $2.5 \pm 1.2 \%$. Figure $2 \mathrm{~b}$ is a SEM image with higher magnification for SP-NiCrBSi. On the one hand, some non-bonded boundaries (as indicated by triangle) are found. On the other hand, a clear coating/substrate interface with several pores is found. These two typical features are frequently found in the plasma-sprayed NiCrBSi coatings $[62,63]$.

According to the EDS results listed in Figure 2g, the large white blocks (as indicated by hollow arrows) are WC blocks. Such blocks are uniformly distributed in the coating. The pores are also found. The porosity of SP-NW35 $2.3 \pm 0.9 \%$, which is slightly lower than that of SP-NiCrBSi. The inset is an enlarged view of dash rectangle in Figure 2c. It can be found that the WC blocks are discretely distributed in the matrix. Such a microstructure of sprayed NiCrBSi/WC composite coating has also been reported in the Reference [64]. Similar to SP-NiCrBSi, a clear coating/substrate interface and non-bonded boundaries are found in SP-NW35 (Figure 2d). 

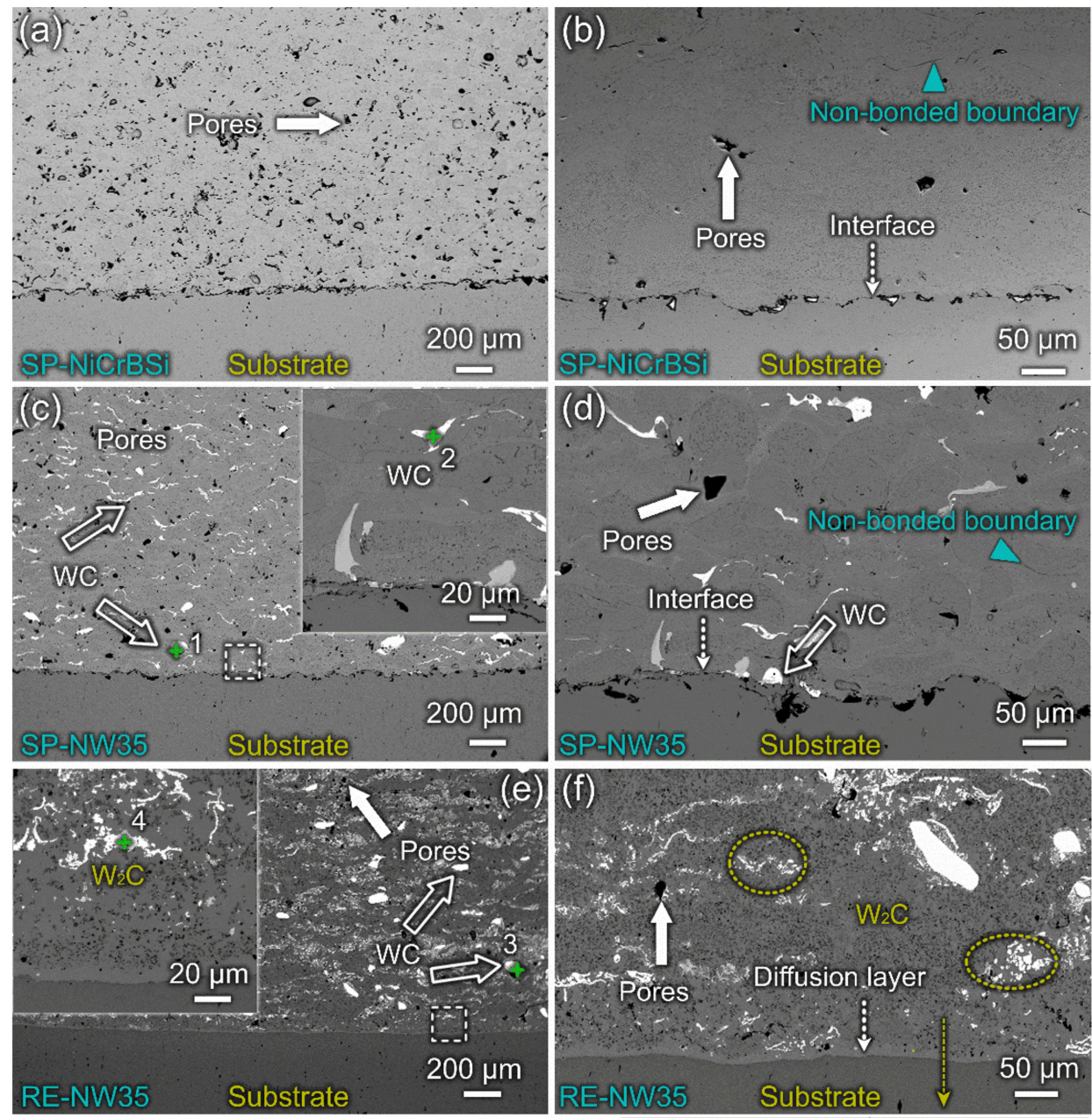

(g)

EDS results of marked points (at.\%)

\begin{tabular}{|c|c|c|c|c|}
\hline \multicolumn{5}{|c|}{ Elements Point- 1 Point- 2 Point- 3 Point- 4} \\
\hline $\mathrm{Ni}$ & 14.83 & 63.81 & 1.85 & 38.37 \\
\hline $\mathrm{Cr}$ & 1.53 & 1.84 & 6.09 & 10.03 \\
\hline B & - & - & 3.41 & - \\
\hline $\mathrm{Si}$ & - & 0.32 & 1.01 & 0.56 \\
\hline $\mathrm{Fe}$ & 0.94 & 1.23 & 3.61 & 0.81 \\
\hline W & 40.45 & 16.55 & 40.56 & 30.90 \\
\hline C & 42.25 & 16.25 & 43.47 & 19.33 \\
\hline
\end{tabular}

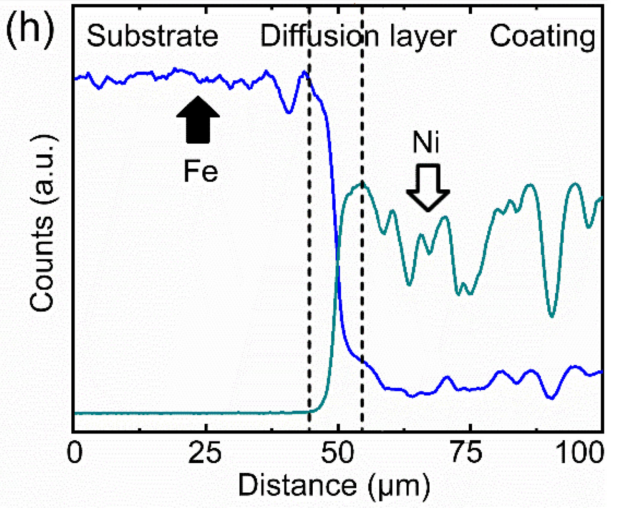

Figure 2. SEM observations for the cross-sectional morphologies of (a,b) SP-NiCrBSi, (c,d) SP-NW35, $(\mathbf{e}, \mathbf{f})$ RE-NW35, (g) EDS results of marked points in (c) and (f), and (h) the line scanning profiles of Ni and Fe elements at the interface of the RE-NW35 as marked by yellow arrow in (f). The insets are the enlarged views of dash rectangles in (c) and (e).

The microstructure of RE-NW35 is significantly different to that of SP-NW35 (Figure 2e,f). The non-bonded boundaries are almost absent and the pores become fewer and smaller in RE-NW35. The porosity of RE-NW35 is $1.0 \pm 0.3 \%$. Such a morphology of coating indicates the improved cohesion of the coating [47]. The large white block (point 3) is identified as WC. However, there are a considerable number of small white particles distributed in the vicinity of WC blocks. As seen from the enlarged view of dash rectangle in Figure 2e, the small white dots are discrete ones. The EDS result (point 4) indicates that such small white dots may be small $\mathrm{W}_{2} \mathrm{C}$ particles. Similar feature of $\mathrm{WC} / \mathrm{W}_{2} \mathrm{C}$ particles 
is also observed in Figure $2 \mathrm{f}$. It has been reported that the decarbonization of $\mathrm{WC} \rightarrow \mathrm{W}_{2} \mathrm{C}+\mathrm{C}$ would take place at a high temperature [64,65]. Kıliçay et al. [65] pointed out that the Gibbs free energy of WC formation is $-0.04 \mathrm{~kJ} / \mathrm{mol}$ at $1200{ }^{\circ} \mathrm{C}$, which is slightly lower than that of $\mathrm{W}_{2} \mathrm{C}$ formation $\left(-0.03 \mathrm{~kJ} / \mathrm{mol}\right.$ at $\left.1200{ }^{\circ} \mathrm{C}\right)$. However, $\mathrm{Cr}$ may draw $\mathrm{C}$ from WC to form a chrome carbide structure at a high temperature [65]. Therefore, a relatively high content of $\mathrm{Cr}$ is observed from the EDS result of point 4. As such, WC would be converted to $\mathrm{W}_{2} \mathrm{C}$ with decreasing $\mathrm{C}$ content. This finding is consistent with the result of XRD and also illustrates that the remelting process does not only acts on the $\mathrm{NiCrBSi}$ matrix but also has considerable effects on the WC particles. Furthermore, a diffusion layer is observed at the coating/substrate interface. According to the EDS line scanning result (through the yellow arrow in Figure 2f), Fe and Ni gradually increase or decrease from the coating area to the substrate area. The width of the diffusion layer is about $11 \mu \mathrm{m}$.

\subsection{Adhesion Strength}

Figure 3 shows the adhesion strength of various samples. The adhesion strength of SP-NiCrBSi, and SP-NW35 are $24 \pm 5 \mathrm{MPa}$ and $25 \pm 7 \mathrm{MPa}$, respectively. Therefore, one can conclude that the addition of WC-Ni powder in the NiCrBSi feedstock does not facilitates the improvement of the adhesion strength of SP-NW35. Such a result may be attributed to the similar coating/substrate interfaces in SP-NiCrBSi, and SP-NW35 (Figure 2d,f). In comparison, the RE-NW35 shows a higher adhesion strength of $61 \pm 6 \mathrm{MPa}$, which reaches the limitation of the glue used. The actual adhesion strength of RE-NW35 should be higher than $61 \pm 6 \mathrm{MPa}$, which could not be exactly measured by the method used in this work. Such results substantially demonstrate the improvement in the adhesion strength. As the result presented in [47], if there is a diffusion layer presented at the coating/substrate interface, the adhesion strength would be significantly improved. The results of adhesion strength for various samples were used to illustrate the difference in their coating/substrate interface, but not the main focus of this work.

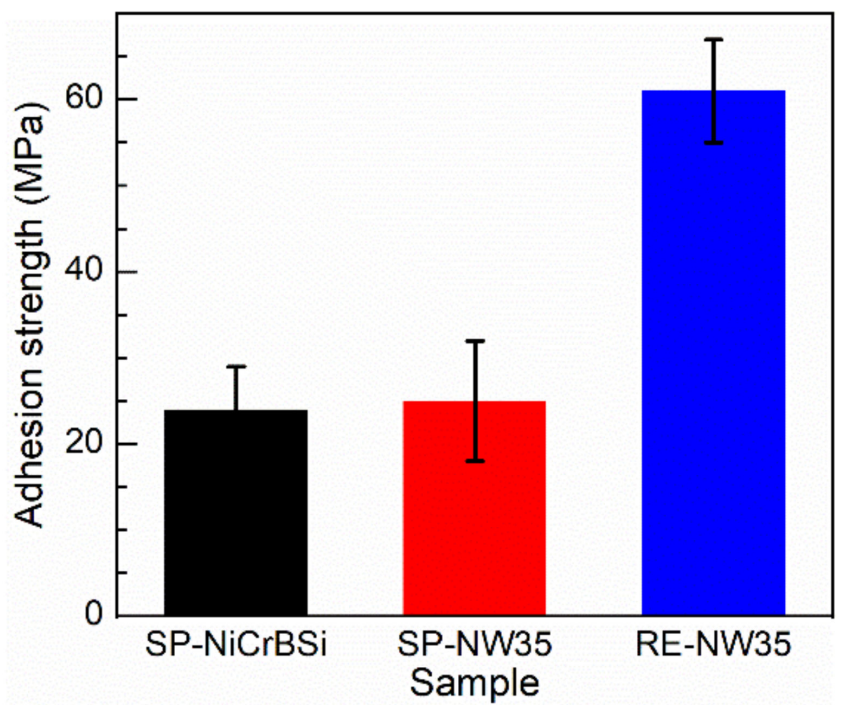

Figure 3. Adhesion strength of the SP-NiCrBSi, SP-NW35 and RE-NW35 coatings.

\subsection{Hardness}

Figure 4 demonstrates the hardness distributions of the SP-NiCrBSi, SP-NW35 and RE-NW35 samples from coating to the substrate. The average hardness of substrate of SP-NiCrBSi, SP-NW35 is significantly low, which is only $240 \pm 10 \mathrm{HV}$. The average hardness of the SP-NiCrBSi coating is $674 \pm 41 \mathrm{HV}$, which is 2.8 times of that of the substrate. The average hardness value of SP-NW35 coating is $785 \pm 73 \mathrm{HV}$, which is 3.3 times of that of the substrate hardness. The increased hardness of the $\mathrm{SP}-\mathrm{NiCrBSi}$ coating is attributed to the strengthening effect of reinforcements. The average hardness of 
the RE-NW35 coating is $1061 \pm 107 \mathrm{HV}$, which is almost 4.4 times of that of the substrate. There are several reasons accounting for the improved hardness of RE-NW35. First, the porosity of coating is significantly reduced after remelting and the cohesion of coating is improved. Second, as observed in Figures 1 and 2, the dispersed $\mathrm{W}_{2} \mathrm{C}$ particles are produced after remelting. Compared with the data in our previous work, the remelted NiCrBSi coating has a hardness of 771-825 HV [47]. Therefore, the increased hardness of RE-NW35 $(1061 \pm 107 \mathrm{HV})$ compared with the hardness data of the remelted NiCrBSi coating (771-825 HV) should be attributed to the dispersion strengthening of WC and $\mathrm{W}_{2} \mathrm{C}$ particles. $\mathrm{W}_{2} \mathrm{C}$ has a higher hardness than WC [33]. As such, dispersed particles with higher hardness result in greater difficulty in the deformation of the coating during hardness test. Under a synergistic effect of the dispersion strengthening and the change in the microstructure, the hardness of RE-NW35 coating is therefore significantly enhanced. Such a phenomenon is frequently observed in the metallic materials [66-71]. Furthermore, it is interesting that the hardness of the substrate increases from $240 \pm 10$ to $560 \pm 11 \mathrm{HV}$ after remelting. Such a phenomenon is also found in our previous work [47], which is attributed to the diffusion of $\mathrm{Ni}$ from coating to the substrate and hence produce solid-solution strengthening. There may be other factor influencing the hardness the substrate in the vicinity of interface after remelting. However, the hardness of substrate may not affect the performance of the remelted RE-NW35 coating to some extent.

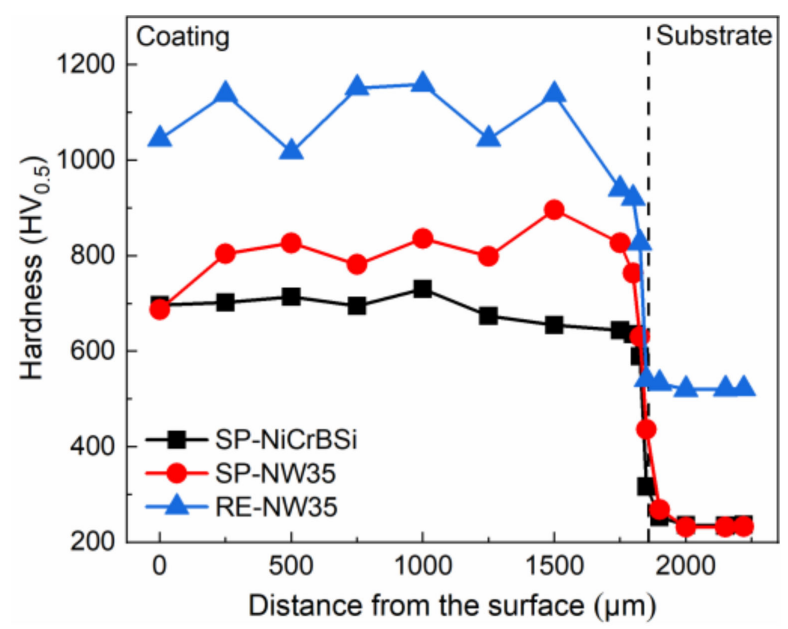

Figure 4. Hardness of the cross-section of the SP-NiCrBSi, SP-NW35 and RE-NW35 coatings.

\subsection{Wear Performance}

Figure 5 shows the friction coefficients of the substrate, SP-NiCrBSi, SP-NW35, and RE-NW35 coating samples vs. time at $600{ }^{\circ} \mathrm{C}$. After the run-in period, the friction coefficients are basically stable and all curves are fluctuated in a small range (Figure 5a). This is consistent with the outcome in literature [72]. It has been reported that the friction coefficient has a relatively small fluctuation and maintains stable after a short running-in period when sliding against $\mathrm{Si}_{3} \mathrm{~N}_{4}$ [72]. For a quantitative comparison, the stable friction coefficients were calculated. Figure $5 b$ shows that the average friction coefficients of the SP-NiCrBSi coating and the SP-NW35 coating are $0.342 \pm 0.021$ and $0.326 \pm 0.042$, respectively, which are lower than that of the substrate $(0.415 \pm 0.025)$. The average friction coefficient of RE-NW35 sample is $0.243 \pm 0.015$, which is the lowest in all samples. It is known that the friction coefficient is defined as the ratio of friction force and normal load between the friction pair and the tested sample [73]. The normal loads are $25 \mathrm{~N}$ in this work for all samples. However, the friction force is complicated and related to surface roughness, shear properties of the samples, the substances between two surfaces, etc. [73]. All samples tests are polished before tribology test and hence they have similar surface roughness. As such, the primary difference in the friction forces of the samples result from the coating themselves. Although it can be understood that the RE-NW35 sample has the reduced friction force during the tribology test, the detailed reason may be understood by combining 
the microstructure of coating and the worn surface after tribology test, which will be discussed in the following paragraphs.
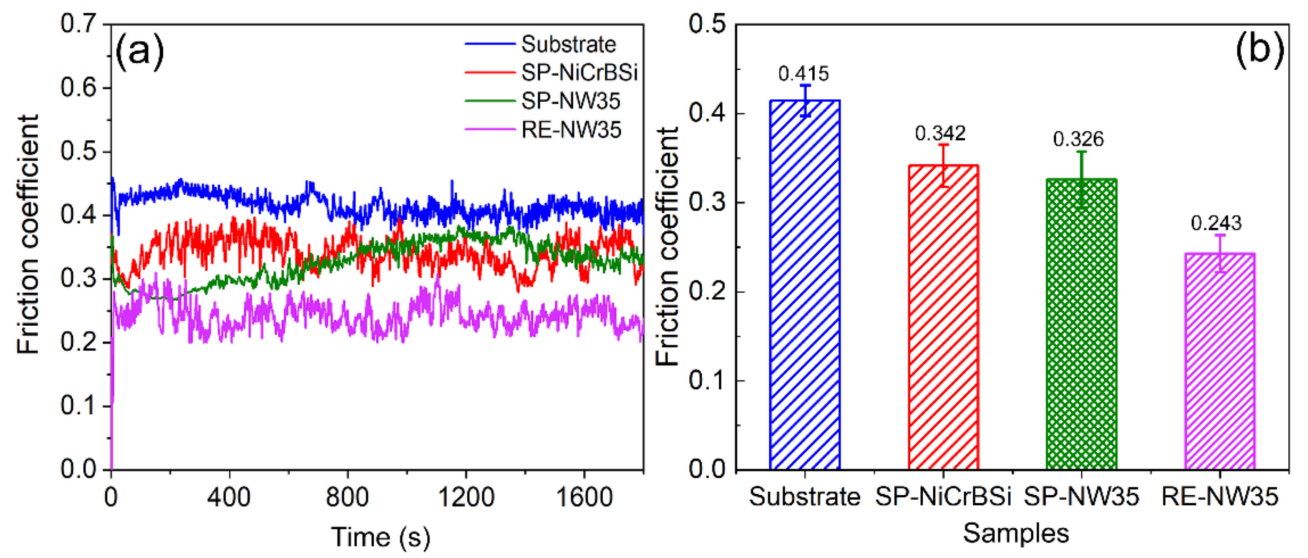

Figure 5. (a) friction coefficient curves and (b) their average values at $600{ }^{\circ} \mathrm{C}$ of SP-NiCrBSi, SP-NW35 and RE-NW35 coating samples.

Figure 6 shows the wear volumes of the substrate, SP-NiCrBSi, SP-NW35 and RE-NW35 samples after tribology tests. The wear volumes of the substrate, the SP-NiCrBSi coating and the SP-NW35 coatings at the high temperature are significantly higher than that of the RE-NW35 coating. It is found that the wear volume of SP-NiCrBSi is $2.072 \pm 0.42 \mathrm{~mm}^{3}$, which is lower than the wear volume of the substrate $\left(2.437 \pm 0.23 \mathrm{~mm}^{3}\right)$. The wear volume of SP-NW35 is $1.884 \pm 0.02 \mathrm{~mm}^{3}$, which is slightly lower than that of SP-NiCrBSi, indicating that the WC has a strengthening effect on the high-temperature wear resistance. In comparison, the wear volume of the RE-NW35 coating is $0.629 \pm 0.02 \mathrm{~mm}^{3}$, which is only a quarter of that substrate and one-third of that of SP-NW35 coating. Therefore, one can conclude that the remelting process not only decreases the friction coefficient of $\mathrm{NiCrBSi} / \mathrm{WC}$ composite coating but also reduces its wear volume. Therefore, the RE-NW35 sample has good high-temperature wear resistance.

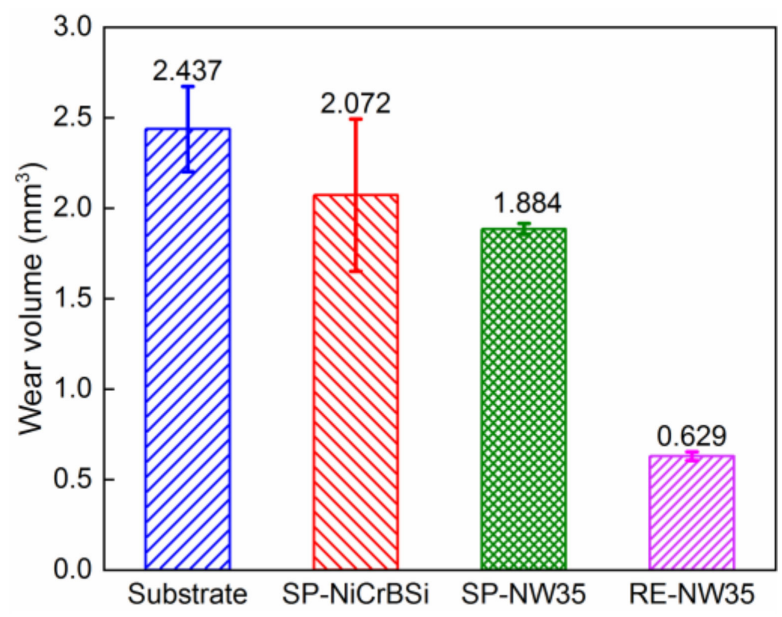

Figure 6. Wear volumes of the substrate, the SP-NiCrBSi, SP-NW35 and RE-NW35 coatings at $600{ }^{\circ} \mathrm{C}$.

Figure 7 shows SEM images of worn surfaces and debris of the SP-NiCrBSi, SP-NW35 and RE-NW35 coatings after tribology tests at $600{ }^{\circ} \mathrm{C}$. Tables 3 and 4 list the chemical compositions of worn surfaces and debris as indicated in Figure 7. Abrasive wear and cracks are observed on the worn surface of SP-NiCrBSi, indicating the presence of severe deformation (Figure 7a). As listed in Table 3, the worn surface of SP-NiCrBSi has no apparent oxidation (EDS result of the worn surface in the dash rectangle). Meanwhile, Figure $7 \mathrm{~b}$ shows two types of debris for SP-NiCrBSi. Besides the fine debris, 
large flakes with the size of about $100 \mu \mathrm{m}$ are found (Figure $7 \mathrm{~b}$ ). High content of $\mathrm{O}$ (about $8.82 \mathrm{wt} . \%$ ) is found in such flakes. Such a finding indicates that the oxidized part on the SP-NiCrBSi is prone to peel off during the tribology test. The fine debris has the similar composition to the composition of raw material as listed in Table 1. Similar worn surface with slender scratch as well as the chemical composition are observed for SP-NW35 (Figure 7c). In comparison to SP-NiCrBSi, no large flakes are found in the debris of SP-NW35 (Figure 7d). Besides fine debris, plentiful blocks with the size of $10 \mu \mathrm{m}$ are found. EDS result show that such a block contains $88.56 \mathrm{wt} . \% \mathrm{~W}$, which is considered as a WC particle (SP-NiCrBSi-1, Table 4). Such a finding illustrates that WC particles drop off from the SP-NW35 during tribology test. The dropped particles may become abrasive and deteriorate the worn surface of SP-NW35. Therefore, although SP-NW35 has higher hardness than SP-NiCrBSi, SP-NW35 has only slightly lower wear volume than SP-NiCrBSi. The fine debris in Figure $7 \mathrm{~d}$ also contains a certain content of $\mathrm{W}$ and $\mathrm{C}$. Such fine debris is speculated to be the mixture of NiCrBSi matrix and small W-C compound particles (such as $\mathrm{WC}$ and $\mathrm{W}_{2} \mathrm{C}$ ). As shown in Figure 6e, shallow scratch and plough are observed on the worn surface of RE-NW35 coating, indicating the occurrence of abrasive wear. The O content of the worn surface of RE-NW35 (3.13 wt.\%) is comparable to those of SP-NiCrBSi and SP-NW35 (3.70 wt.\% and $3.42 \mathrm{wt} . \%)$. Nevertheless, no cracks are observed on the worn surface of RE-NW35 coating, which may be attributed to the reduced pores. Flat-block debris are found for RE-NW35 (Figure 7f). The EDS result show that such debris contains more than $50 \mathrm{wt} . \% \mathrm{~W}$ and more than $30 \% \mathrm{wt} . \% \mathrm{Ni}$. Combining the result of phase constituent (Figure 1) and microstructure of RE-NW35 (Figure 2e,f), such debris may also be the mixture of NiCrBSi matrix and $\mathrm{WC} / \mathrm{W}_{2} \mathrm{C}$ particles. However, such a morphology of debris is significantly different from the fine debris of SP-NW35 (Figure 7d). It is interesting that the RE-NW35 has a significantly lower wear volume compared with SP-NiCrBSi and SP-NW35. For the improvement of wear resistance, it may result from a synergistic effect of many aspects. First of all, it can be understood that the microstructure of RE-NW35 is significantly different from those of SP-NiCrBSi and SP-NW35. The RE-NW35 has a lower porosity and almost no non-bonded boundaries. It has been reported that the cavities or voids in the coating would sustain the more stress and the coatings would be worn more easily during the tribology test [74]. Therefore, cracks are found on the worn surfaces of SP-NiCrBSi and SP-NW35 but not on the worn surface of RE-NW35. Meanwhile, the abrasive wear features found on the worn surfaces of all samples, indicating the three-body abrasion process [75]. The plough or scratch found on the worn surfaces illustrate that the wear process is governed by micro-cutting [76]. It is known that the resistance of the coatings to micro-cutting would be enhanced due to the improved hardness of the materials [76]. Hence, the RE-NW35 sample with higher hardness has a higher ability against the micro-cutting during tribology test. As such, due to these two main reasons, the RE-NW35 coating possesses better wear resistance than the other two counterparts.

Table 3. Chemical Compositions of Worn Surfaces in the Dash Rectangles in Figure 7 (wt.\%).

\begin{tabular}{ccccccccc}
\hline & Fe & Cr & Ni & O & Si & C & B & W \\
\hline SP-NiCrBSi & 3.87 & 16.5 & 69.36 & 3.70 & 3.89 & 2.69 & - & - \\
SP-NW35 & 4.16 & 17.65 & 65.39 & 3.42 & 2.58 & 2.72 & - & 6.79 \\
RE-NW35 & 3.74 & 17 & 57.01 & 3.13 & 2.96 & 6.10 & - & 12.76 \\
\hline
\end{tabular}

Table 4. Chemical Compositions of Debris as Marked in Figure 7 (wt.\%).

\begin{tabular}{ccccccccc}
\hline & Fe & Cr & Ni & O & Si & C & B & W \\
\hline SP-NiCrBSi-1 & 4.20 & 16.15 & 64.58 & 8.82 & 3.43 & 2.82 & 0.36 & - \\
SP-NiCrBSi-2 & 3.62 & 16.23 & 64.20 & 3.59 & 3.03 & 8.97 & - & - \\
SP-NW35-1 & 0.48 & 0.94 & 2.18 & 1.62 & 0.36 & 5.86 & - & 88.56 \\
SP-NW35-2 & 3.46 & 10.67 & 49.62 & 4.78 & 3.01 & 2.74 & 0.45 & 22.38 \\
RE-NW35 & 1.87 & 3.36 & 32.13 & 6.33 & 0.48 & 3.15 & 1.79 & 50.89 \\
\hline
\end{tabular}



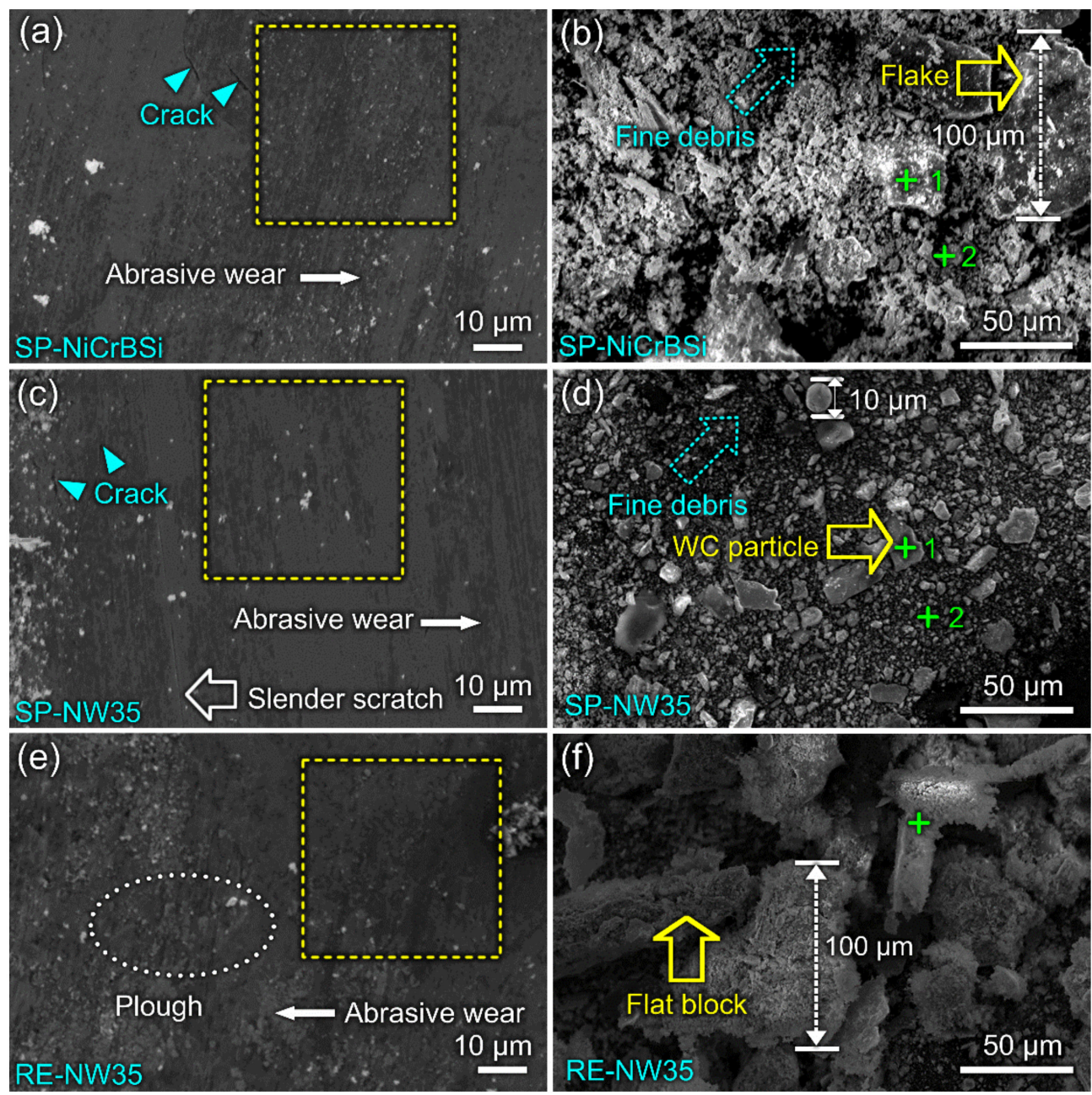

Figure 7. SEM images of worn surfaces $(\mathbf{a}, \mathbf{c}, \mathbf{e})$ and debris $(\mathbf{b}, \mathbf{d}, \mathbf{f})$ of SP-NiCrBSi, SP-NW35 and RE-NW35 coatings after tribology tests at $600{ }^{\circ} \mathrm{C}$.

\section{Conclusions}

In this work, the plasma-sprayed $\mathrm{NiCrBSi} / \mathrm{WC}$ composite coating was remelted using the plasma arc. The microstructures and properties of both as-sprayed and remelted NiCrBSi/WC composite coatings (denoted as SP-NW35 and RE-NW35, respectively) were investigated by X-ray diffraction, scanning electron microscopy, hardness test and tribology test. The as-sprayed NiCrBSi coating (SP-NiCrBSi) was used as the reference. Some key conclusions were drawn and are as follows:

1. The SP-NiCrBSi coating shows a typical plasma-sprayed coating structure with a certain number of pores. The SP-NW35 coating primarily contains the WC reinforcements. After remelting, decarburization of WC takes place, resulting in the formation of $\mathrm{W}_{2} \mathrm{C}$ particles in the RE-NW35. The remelting process also reduces the pores and eliminates the non-bonded boundaries in the RE-NW35.

2. The average hardness of the SP-NiCrBSi, SP-NW35 and RE-NW35 coatings is $673.82 \pm 40.56$, $785.14 \pm 72.79$ and $1061.23 \pm 107.23 \mathrm{HV}$, respectively. The improved hardness of SP-NW35 is mainly attributed to the presence of reinforcements of WC. The hardness of RE-NW35 is significantly improved, which is attributed to the dispersion strengthening produced by small $\mathrm{W}_{2} \mathrm{C}$ particles, the reduction of pores and elimination of the non-bonded boundaries.

3. The tribology result shows that the friction coefficients of the three coatings are $0.342 \pm 0.021,0.326$ \pm 0.042 and $0.243 \pm 0.015$, respectively, at $600^{\circ} \mathrm{C}$. The SP-NiCrBSi and SP-NW35 coatings display comparable wear volumes of $2.072 \pm 0.42$ and $1.884 \pm 0.02 \mathrm{~mm}^{3}$, respectively. Although SP-NW35 
has higher hardness than SP-NiCrBSi, the dropped WC particles during the tribology test may become abrasive, degrading the wear resistance of SP-NW35. After the remelting, the RE-NW35 coating possesses lower wear volume of $0.629 \pm 0.02 \mathrm{~mm}^{3}$ as compared to the other two coating samples. The reduced pores in RE-NW35 decrease the cracking susceptibility and the increased hardness of RE-NW35 could against the micro-cutting during tribology.

Author Contributions: Conceptualization: J.S., L.-Y.C. and S.-H.M.; methodology: S.L.; software: Y.-T.L., and Z.-X.W.; formal analysis: L.-Y.C. and Y.-T.L.; resources: S.L.; data curation: J.S., Q.-H.Z. and Z.-J.Y.; writing—original draft preparation: J.S.; writing—review and editing: L.-Y.C. and L.-C.Z.; writing-manuscript finalization: J.S., S.L., L.-Y.C. and L.-C.Z.; supervision: S.L. and L.-Y.C.; project administration: S.L. and L.-Y.C.; funding acquisition: S.L. and L.-Y.C. All authors have read and agreed to the published version of the manuscript.

Funding: The authors would like to acknowledge the financial support provided by Jiangsu Province Six Talent Peaks Project (XCL-117), Natural Science Foundation of Jiangsu Province (SBK2020022404). Open Foundation of Guangxi Key Laboratory of Processing for Non-ferrous Metals and Featured Materials, (Grant No. 2020GXYSOF01, 2019GXYSOF01).

Conflicts of Interest: The authors declare no conflict of interest. The funders had no role in the design of the study; in the collection, analyses, or interpretation of data; in the writing of the manuscript; or in the decision to publish the results.

\section{References}

1. Liang, Q.; Liu, X.; Li, P.; Ding, P.; Zhang, X. Development and application of high-temperature constitutive model of HNi55-7-4-2 alloy. Metals 2020, 10, 1250. [CrossRef]

2. Sang, P.; Chen, L.-Y.; Zhao, C.; Wang, Z.-X.; Wang, H.; Lu, S.; Song, D.; Xu, J.-H.; Zhang, L.-C. Particle size-dependent microstructure, hardness and electrochemical corrosion behavior of atmospheric plasma sprayed NiCrBSi coatings. Metals 2019, 9, 1342. [CrossRef]

3. Chen, L.-Y.; Xu, T.; Wang, H.; Sang, P.; Lu, S.; Wang, Z.-X.; Chen, S.; Zhang, L.-C. Phase interaction induced texture in a plasma sprayed-remelted NiCrBSi coating during solidification: An electron backscatter diffraction study. Surf. Coat. Technol. 2019, 358,467-480. [CrossRef]

4. Chen, L.-Y.; Xu, T.; Lu, S.; Wang, Z.-X.; Chen, S.; Zhang, L.-C. Improved hardness and wear resistance of plasma sprayed nanostructured NiCrBSi coating via short-time heat treatment. Surf. Coat. Technol. 2018, 350, 436-444. [CrossRef]

5. Xiang, K.; Chen, L.-Y.; Chai, L.; Guo, N.; Wang, H. Microstructural characteristics and properties of CoCrFeNiNbx high-entropy alloy coatings on pure titanium substrate by pulsed laser cladding. Appl. Surf. Sci. 2020, 517, 146214. [CrossRef]

6. Chen, K.; Zeng, L.; Li, Z.; Chai, L.; Wang, Y.; Chen, L.-Y.; Yu, H. Effects of laser surface alloying with Cr on microstructure and hardness of commercial purity Zr. J. Alloys Compd. 2019, 784, 1106-1112. [CrossRef]

7. Chai, L.J.; Wang, S.Y.; Wu, H.; Guo, N.; Pan, H.C.; Chen, L.Y.; Murty, K.L.; Song, B. $\alpha \rightarrow \beta$ Transformation characteristics revealed by pulsed laser-induced non-equilibrium microstructures in duplex-phase $\mathrm{Zr}$ alloy. Sci. China Tech. Sci. 2017, 60, 1255-1262. [CrossRef]

8. Chai, L.; Chen, K.; Zhi, Y.; Murty, K.L.; Chen, L.Y.; Yang, Z. Nanotwins induced by pulsed laser and their hardening effect in a Zr alloy. J. Alloys Compd. 2018, 748, 163-170. [CrossRef]

9. Wang, L.; Xie, L.; Lv, Y.; Zhang, L.-C.; Chen, L.; Meng, Q.; Qu, J.; Zhang, D.; Lu, W. Microstructure evolution and superelastic behavior in $\mathrm{Ti}_{-35} \mathrm{Nb}_{-2} \mathrm{Ta}_{3} \mathrm{Zr}$ alloy processed by friction stir processing. Acta Mater. 2017, 131, 499-510. [CrossRef]

10. Wang, L.; Qu, J.; Chen, L.; Meng, Q.; Zhang, L.C.; Qin, J.; Zhang, D.; Lu, W. Investigation of deformation mechanisms in $\beta$-Type $\mathrm{Ti}_{-35} \mathrm{Nb}_{2} \mathrm{Ta}_{3} \mathrm{Zr}$ Alloy via FSP leading to surface strengthening. Metall. Mater. Trans. A 2015, 46, 4813-4818. [CrossRef]

11. Wang, Z.-X.; Chen, G.-Q.; Chen, L.-Y.; Xu, L.; Lu, S. Degradation behavior of micro-arc oxidized ZK60 magnesium alloy in a simulated body fluid. Metals 2018, 8, 724. [CrossRef]

12. Jambor, M.; Trško, L.; Klusák, J.; Fintová, S.; Kajánek, D.; Nový, F.; Bokůvka, O. Effect of severe shot peening on the very-high cycle notch fatigue of an AW 7075 alloy. Metals 2020, 10, 1262. [CrossRef] 
13. Liu, Y.; Cao, Y.; Zhou, H.; Chen, X.; Liu, Y.; Xiao, L.; Huan, X.; Zhao, Y.; Zhu, Y. Mechanical properties and microstructures of commercial-purity aluminum processed by rotational accelerated shot peening plus cold rolling. Adv. Eng. Mater. 2020, 22, 1900478. [CrossRef]

14. Pawlowski, L. Finely grained nanometric and submicrometric coatings by thermal spraying: A review. Surf. Coat. Technol. 2008, 202, 4318-4328. [CrossRef]

15. Song, Y.S.; Lee, I.-G.; Lee, D.Y.; Kim, D.-J.; Kim, S.; Lee, K. High-temperature properties of plasma-sprayed coatings of YSZ/NiCrAlY on Inconel substrate. Mater. Sci. Eng. A 2002, 332, 129-133. [CrossRef]

16. Nishinoiri, S.; Enoki, M.; Tomita, K. In situ monitoring of microfracture during plasma spray coating by laser AE technique. Sci. Tech. Adv. Mater. 2003, 4, 623-631. [CrossRef]

17. Verné, E.; Ferraris, M.; Ventrella, A.; Paracchini, L.; Krajewski, A.; Ravaglioli, A. Sintering and plasma spray deposition of bioactive glass-Matrix composites for medical applications. J. Eur. Ceram. Soc. 1998, 18, 363-372. [CrossRef]

18. Zhang, L.C.; Chen, L.Y. A review on biomedical titanium alloys: Recent progress and prospect. Adv. Eng. Mater. 2019, 21, 1801215. [CrossRef]

19. Zhang, L.-C.; Chen, L.-Y.; Wang, L. Surface modification of titanium and titanium alloys: Technologies, developments and future interests. Adv. Eng. Mater. 2020, 22, 1901258. [CrossRef]

20. Otsubo, F.; Era, H.; Kishitake, K. Structure and phases in nickel-base self-fluxing alloy coating containing high chromium and boron. J. Therm. Spray Technol. 2000, 9, 107-113. [CrossRef]

21. Lei, J.; Shi, C.; Zhou, S.; Gu, Z.; Zhang, L.C. Enhanced corrosion and wear resistance properties of carbon fiber reinforced Ni-based composite coating by laser cladding. Surf. Coat. Technol. 2018, 334, 274-285. [CrossRef]

22. Shi, C.; Lei, J.; Zhou, S.; Dai, X.; Zhang, L.C. Microstructure and mechanical properties of carbon fibers strengthened Ni-based coatings by laser cladding: The effect of carbon fiber contents. J. Alloys Compd. 2018, 744, 146-155. [CrossRef]

23. Houdková, Š.; Smazalová, E.; Vostřák, M.; Schubert, J. Properties of NiCrBSi coating, as sprayed and remelted by different technologies. Surf. Coat. Technol. 2014, 253, 14-26. [CrossRef]

24. Singh, H.; Sidhu, B.S.; Puri, D.; Prakash, S. Use of plasma spray technology for deposition of high temperature oxidation/corrosion resistant coatings-A review. Mater. Corros. 2007, 58, 92-102. [CrossRef]

25. Planche, M.P.; Liao, H.; Normand, B.; Coddet, C. Relationships between NiCrBSi particle characteristics and corresponding coating properties using different thermal spraying processes. Surf. Coat. Technol. 2005, 200, 2465-2473. [CrossRef]

26. Yang, H.-Y.; Wang, Z.; Yue, X.; Ji, P.-J.; Shu, S.-L. Simultaneously improved strength and toughness of in situ bi-phased TiB2-Ti(C,N)-Ni cermets by Mo addition. J. Alloys Compd. 2019, 820, 153068. [CrossRef]

27. Yang, H.; Yue, X.; Wang, Z.; Shao, Y.; Shu, S. Strengthening mechanism of TiC/Al composites using Al-Ti-C/CNTs with doping alloying elements (Mg, Zn and Cu). J. Mater. Res. Tech. 2020, 9, 6475-6487. [CrossRef]

28. Yang, H.-Y.; Wang, Z.; Shu, S.-L.; Lu, J.-B. Effect of Ta addition on the microstructures and mechanical properties of in situ bi-phase (TiB2-TiCxNy)/(Ni-Ta) cermets. Ceram. Int. 2020, 45, 4408-4417. [CrossRef]

29. Serres, N.; Hlawka, F.; Costil, S.; Langlade, C.; MacHi, F. Microstructures and mechanical properties of metallic $\mathrm{NiCrBSi}$ and composite NiCrBSi-WC layers manufactured via hybrid plasma/laser process. Appl. Surf. Sci. 2011, 257, 5132-5137. [CrossRef]

30. Guo, C.; Zhou, J.; Chen, J.; Zhao, J.; Yu, Y.; Zhou, H. High temperature wear resistance of laser cladding NiCrBSi and NiCrBSi/WC-Ni composite coatings. Wear 2011, 270, 492-498. [CrossRef]

31. Rachidi, R.; Bachir, E.; Delaunois, F.; Vitry, V.; Deschuyteneer, D. Wear performance of thermally sprayed $\mathrm{NiCrBSi}$ and NiCrBSi-WC coatings under two different wear modes. J. Mater. Environ. Sci. 2017, 8, 4550-4559. [CrossRef]

32. Zhu, Z.Q.; Huang-Bin, L.I.; Tan, Y.F.; Gang, W.U.; Tan, H.; Zhang, S.B. Tribological properties of NiCrBSi/WC spray-welding coatings in corrosive mediums. Mach. Build. Automat. 2006, 2. Available online: http: //en.cnki.com.cn/Article_en/CJFDTotal-ZZHD200602021.htm (accessed on 14 December 2020).

33. Zakharova, E.S.; Markova, I.Y.; Maslov, A.L.; Polushin, N.I.; Laptev, A.I. Morphology of powders of tungsten carbide used in wear-resistant coatings and deposition on the PDC drill bits. J. Phys. Conf. 2017, 857, 012058. [CrossRef]

34. Gell, M.; Xie, L.; Ma, X.; Jordan, E.H.; Padture, N.P. Highly durable thermal barrier coatings made by the solution precursor plasma spray process. Surf. Coat. Technol. 2004, 177, 97-102. [CrossRef] 
35. Ahmaniemi, S.; Vuoristo, P.; Mantyla, T.; Gualco, C.; Bonadei, A.; Maggio, R.D. Thermal cycling resistance of modified thick thermal barrier coatings. Surf. Coat. Technol. 2004, 190, 378-387. [CrossRef]

36. Fukumasa, O.; Osaki, K.; Fujimoto, S.; Lungu, C.P.; Lungu, A.M. Low friction coatings prepared by high performance type spray gun. Surf. Coat. Technol. 2003, 169-170, 415-418. [CrossRef]

37. Li, H.; Khor, K.; Yu, L.; Cheang, P. Microstructure modifications and phase transformation in plasma-sprayed WC-Co coatings following post-spray spark plasma sintering. Surf. Coat. Technol. 2005, 194, 96-102. [CrossRef]

38. Calin, M.; Zhang, L.C.; Eckert, J. Tailoring of microstructure and mechanical properties of a Ti-based bulk metallic glass-forming alloy. Scripta Mater. 2007, 57, 1101-1104. [CrossRef]

39. Yu, P.; Zhang, L.C.; Zhang, W.Y.; Das, J.; Kim, K.B.; Eckert, J. Interfacial reaction during the fabrication of Ni60Nb40 metallic glass particles-reinforced Al based MMCs. Mater. Sci. Eng. A 2007, 444, 206-213. [CrossRef]

40. Zhang, L.C.; Jia, Z.; Lyu, F.; Liang, S.X.; Lu, J. A review of catalytic performance of metallic glasses in wastewater treatment: Recent progress and prospects. Prog. Mater. Sci. 2019, 105, 100576. [CrossRef]

41. Zhang, L.C.; Xu, J.; Ma, E. Consolidation and properties of ball-milled Ti50Cu18Ni22Al4Sn6 glassy alloy by equal channel angular extrusion. Mater. Sci. Eng. A 2006, 434, 280-288. [CrossRef]

42. Jia, Z.; Duan, X.; Zhang, W.; Wang, W.; Sun, H.; Wang, S.; Zhang, L.-C. Ultra-sustainable Fe78Si9B13 metallic glass as a catalyst for activation of persulfate on methylene blue degradation under UV-Vis light. Sci. Rep. 2016, 6, 38520. [CrossRef] [PubMed]

43. Zhang, L.C.; Shen, Z.Q.; Xu, J. Mechanically milling-induced amorphization in Sn-containing Ti-based multicomponent alloy systems. Mater. Sci. Eng. A 2005, 394, 204-209. [CrossRef]

44. Zhang, L.-C.; Xu, J.; Eckert, J. Thermal stability and crystallization kinetics of mechanically alloyed TiC/Ti-based metallic glass matrix composite. J. Appl. Phys. 2006, 100, 033514. [CrossRef]

45. Zhang, L.C.; Xu, J. Glass-forming ability of melt-spun multicomponent (Ti, Zr, Hf)-(Cu, Ni, Co)-Al alloys with equiatomic substitution. J. Non-Cryst. Solids 2004, 347, 166-172. [CrossRef]

46. Zhang, L.-C.; Kim, K.B.; Yu, P.; Zhang, W.Y.; Kunz, U.; Eckert, J. Amorphization in mechanically alloyed (Ti, Zr, Nb)-(Cu, Ni)-Al equiatomic alloys. J. Alloys Compd. 2007, 428, 157-163. [CrossRef]

47. Chen, L.-Y.; Wang, H.; Zhao, C.; Lu, S.; Wang, Z.-X.; Sha, J.; Chen, S.; Zhang, L.-C. Automatic remelting and enhanced mechanical performance of a plasma sprayed NiCrBSi coating. Surf. Coat. Technol. 2019, 369, 31-43. [CrossRef]

48. Serres, N.; Hlawka, F.o.; Costil, S.; Langlade, C.; Machi, F. Microstructures of Metallic NiCrBSi Coatings Manufactured via Hybrid Plasma Spray and In Situ Laser Remelting Process. J. Therm. Spray Technol. 2011, 20, 336-343. [CrossRef]

49. Miao, S.M.; Lei, M.K. Surface morphology of $\mathrm{Cr}_{2} \mathrm{O}_{3}$ coatings on steel irradiated by high-intensity pulsed ion beam. Nucl. Instrum. Methods Phys. Res. 2006, 243, 335-339. [CrossRef]

50. Iwaszko, J. Surface remelting treatment of plasma-sprayed $\mathrm{Al}_{2} \mathrm{O}_{3}+13$ wt. $\% \mathrm{TiO}_{2}$ coatings. Surf. Coat. Technol. 2006, 201, 3443-3451. [CrossRef]

51. Cui, C.; Ye, F.; Song, G. Laser surface remelting of Fe-based alloy coatings deposited by HVOF. Surf. Coat. Technol. 2012, 206, 2388-2395. [CrossRef]

52. Wu, Y.Z.; Liao, W.-B.; Wang, F.; Wang, M.-L.; Yu, C.-Y.; Wang, Z.; Guo, Z.-X.; Liu, Z.-Y.; Cao, Y.-B.; Huang, J.-J. Effect of electron beam remelting treatments on the performances of plasma sprayed zirconia coatings. J. Alloys Compd. 2018, 756, 33-39. [CrossRef]

53. Tian-shun, D.; Li, L.; Bin-guo, F.; Guo-lu, L.; Hai-dou, W.; Yang, F. Investigation of rolling/sliding contact fatigue behaviors of induction remelted Ni-based coating. Surf. Coat. Technol. 2019, 372, 451-462. [CrossRef]

54. ASTM. Standard Test Methods for Determining Area Percentage Porosity in Thermal Sprayed Coatings; ASTM International: West Conshohocken, PA, USA, 2014; E2109-01; Available online: http://www.astm.org (accessed on 14 December 2020).

55. Tian, J.J.; Yao, S.W.; Luo, X.T.; Li, C.X.; Li, C.J. An effective approach for creating metallurgical self-bonding in plasma-spraying of NiCr-Mo coating by designing shell-core-structured powders. Acta Mater. 2016, 110, 19-30. [CrossRef]

56. Zhang, L.C.; Shen, Z.Q.; Xu, J. Glass formation in a (Ti, Zr, Hf)-(Cu, Ni, Ag)-Al high-order alloy system by mechanical alloying. J. Mater. Res. 2003, 18, 2141-2149. [CrossRef] 
57. Liang, S.X.; Jia, Z.; Liu, Y.J.; Zhang, W.; Wang, W.; Lu, J.; Zhang, L.C. Compelling rejuvenated catalytic performance in metallic glasses. Adv. Mater. 2018, 30, 1802764. [CrossRef]

58. Zhang, L.C.; Xu, J.; Ma, E. Mechanically alloyed amorphous $\mathrm{Ti}_{50}\left(\mathrm{Cu}_{0.45} \mathrm{Ni}_{0.55}\right)_{44-\mathrm{x}} \mathrm{Al}_{\mathrm{X}} \mathrm{Si}_{4} \mathrm{~B}_{2}$ alloys with supercooled liquid region. J. Mater. Res. 2002, 17, 1743-1749. [CrossRef]

59. Voevodin, A.A.; Prasad, S.V.; Zabinski, J.S. Nanocrystalline carbide/amorphous carbon composites. J. Appl. Phys. 1997, 82, 855-858. [CrossRef]

60. Gao, Y.; Song, X.; Liu, X.; Wei, C.; Wang, H.; Guo, G. On the formation of $\mathrm{WC}_{1-\mathrm{x}}$ in nanocrystalline cemented carbides. Scripta Mater. 2013, 68, 108-110. [CrossRef]

61. Pawlak, W.; Kubiak, K.J.; Wendler, B.G.; Mathia, T.G. Wear resistant multilayer nanocomposite $\mathrm{WC}_{1-\mathrm{x}} / \mathrm{C}$ coating on Ti-6Al-4V titanium alloy. Tri. Inter. 2015, 82, 400-406. [CrossRef]

62. Zhang, C.; Liu, L.; Xu, H.; Xiao, J.; Zhang, G.; Liao, H. Role of Mo on tribological properties of atmospheric plasma-sprayed Mo-NiCrBSi composite coatings under dry and oil-lubricated conditions. J. Alloys Compd. 2017, 727, 841-850. [CrossRef]

63. Bergant, Z.; Trdan, U.; Grum, J. Effect of high-temperature furnace treatment on the microstructure and corrosion behavior of NiCrBSi flame-sprayed coatings. Corros. Sci. 2014, 88, 372-386. [CrossRef]

64. Niranatlumpong, P.; Koiprasert, H. Phase transformation of NiCrBSi-WC and NiBSi-WC arc sprayed coatings. Surf. Coat. Technol. 2011, 206, 440-445. [CrossRef]

65. Kılıçay, K.; Buytoz, S.; Ulutan, M. Microstructural and tribological properties of induction cladded NiCrBSi /WC composite coatings. Surf. Coat. Technol. 2020, 397, 125974. [CrossRef]

66. Chen, L.; Li, J.; Zhang, Y.; Zhang, L.C.; Lu, W.; Zhang, L.; Wang, L.; Zhang, D. Effects of alloyed Si on the autoclave corrosion performance and periodic corrosion kinetics in $\mathrm{Zr}-\mathrm{Sn}-\mathrm{Nb}-\mathrm{Fe}-\mathrm{O}$ alloys. Corros. Sci. 2015, 100, 651-662. [CrossRef]

67. Chen, L.; Li, J.; Zhang, Y.; Lu, W.; Zhang, L.C.; Wang, L.; Zhang, D. Effect of low-temperature pre-deformation on precipitation behavior and microstructure of a $\mathrm{Zr}-\mathrm{Sn}-\mathrm{Nb}-\mathrm{Fe}-\mathrm{Cu}-\mathrm{O}$ alloy during fabrication. J. Nucl. Sci. Technol. 2016, 53, 496-507. [CrossRef]

68. Chen, L.-Y.; Cui, Y.-W.; Zhang, L.-C. Recent development in beta titanium alloys for biomedical applications. Metals 2020, 10, 1139. [CrossRef]

69. Chen, L.Y.; Sang, P.; Zhang, L.; Song, D.; Chu, Y.Q.; Chai, L.; Zhang, L.C. Homogenization and growth behavior of second-phase particles in a deformed Zr-Sn-Nb-Fe-Cu-Si-O alloy. Metals 2018, 8, 759. [CrossRef]

70. Rabadia, C.D.; Liu, Y.J.; Zhao, C.H.; Wang, J.C.; Jawed, S.F.; Wang, L.Q.; Chen, L.Y.; Sun, H.; Zhang, L.C. Improved trade-off between strength and plasticity in titanium based metastable beta type Ti-Zr-Fe-Sn alloys. Mater. Sci. Eng. A 2019, 766, 138340. [CrossRef]

71. Chen, L.; Li, J.; Zhang, Y.; Zhang, L.C.; Lu, W.; Wang, L.; Zhang, L.; Zhang, D. Zr-Sn-Nb-Fe-Si-O alloy for fuel cladding candidate: Processing, microstructure, corrosion resistance and tensile behavior. Corros. Sci. 2015, 100, 332-340. [CrossRef]

72. Liu, L.; Xu, H.; Xiao, J.; Wei, X.; Zhang, G.; Zhang, C. Effect of heat treatment on structure and property evolutions of atmospheric plasma sprayed NiCrBSi coatings. Surf. Coat. Technol. 2017, 325, 548-554. [CrossRef]

73. Blau, P.J. The significance and use of the friction coefficient. Tri. Inter. 2001, 34, 585-591. [CrossRef]

74. Deschuyteneer, D.; Petit, F.; Gonon, M.; Cambier, F. Processing and characterization of laser clad NiCrBSi/WC composite coatings-Influence of microstructure on hardness and wear. Surf. Coat. Technol. 2015, 283, 162-171. [CrossRef]

75. Sheppard, P.; Koiprasert, H. Effect of $\mathrm{W}$ dissolution in NiCrBSi-WC and NiBSi-WC arc sprayed coatings on wear behaviors. Wear 2014, 317, 194-200. [CrossRef]

76. Li, G.J.; Li, J.; Luo, X. Effects of high temperature treatment on microstructure and mechanical properties of laser-clad NiCrBSi/WC coatings on titanium alloy substrate. Mater. Charact. 2014, 98, 83-92. [CrossRef]

Publisher's Note: MDPI stays neutral with regard to jurisdictional claims in published maps and institutional affiliations. 